\title{
Impact of sugar-sweetened beverage tax on dental caries: a simulation analysis
}

\author{
Nipaporn Urwannachotima ${ }^{1,2^{*}}$ (D), Piya Hanvoravongchai ${ }^{2}$, John Pastor Ansah ${ }^{3}$, Piyada Prasertsom ${ }^{4}$ and
}

Victoria Rui Ying Koh ${ }^{5}$

\begin{abstract}
Background: The tiered sugar-sweetened beverage (SSB) tax was implemented in Thailand to encourage industries to reduce sugar content in beverages, and consequently reduce sugar consumption in the population. The aim of the study is to explore the expected impact of the new SSB tax policy in Thailand, a middle-income country in Asia, and other alternative policies on oral health outcomes as measured by the prevalence and severity of dental caries among the Thai population.

Methods: A qualitative system dynamics model that captures the complex interrelationships among SSB tax, sugar consumption and dental caries, was elicited through participatory stakeholder engagement. Based on the qualitative model, a quantitative system dynamics model was developed to simulate the SSB tax policy and other alternative scenarios in order to evaluate their impact on dental caries among Thai adults from 2010 to 2040.

Results: Under the base-case scenario, the dental caries prevalence among the Thai population 15 years and older, is projected to increase from $61.3 \%$ in 2010 to $74.9 \%$ by 2040 . Implementation of SSB tax policy is expected to decrease the prevalence of dental caries by only $1 \%$ by 2040, whereas the aggressive policy is projected to decrease prevalence of dental caries by $21 \%$ by 2040 .

Conclusions: In countries where a majority of the sugar consumed is from non-tax sugary food and beverages, especially Asian countries where street food culture is ubiquitous and contributes disproportionately to sugar intake, SSB tax alone is unlikely to have meaningful impact on oral health unless it is accompanied with a comprehensive public health policy that aims to reduce total sugar intake from non-SSB sources.
\end{abstract}

Keywords: Dental caries, Dental public health, Sugar-sweetened beverage tax, Sugar consumption, Computer simulation, System dynamics model, System science

\section{Background}

Despite advances in dental treatment, dental caries is still a major public health problem worldwide, especially among disadvantaged groups in both developing and developed countries. The presence of dental caries has been found to significantly affect oral health related

\footnotetext{
* Correspondence: mefeng@gmail.com

'Department of Community Dentistry, Faculty of Dentistry, Chulalongkorn University, Bangkok, Thailand

${ }^{2}$ Department of Preventive and Social Medicine, Faculty of Medicine, Chulalongkorn University, Bangkok, Thailand

Full list of author information is available at the end of the article
}

quality of life and can lead to the eventual loss of teeth [1]. Symptoms of dental caries can not only lead to psychological stress [2] but also decrease school or work productivity of both young and older adults [3]. Current evidence supports the association between high quantity and frequent sugar consumption and high prevalence of dental caries $[4,5]$.

Sugar consumption in Thailand has increased significantly from $12.7 \mathrm{~kg}$ per capita per year in 1983 to 38.2 $\mathrm{kg}$ per capita per year in 2015 [6,7]. The amount of direct sugar consumption from refined table sugar has been

(c) The Author(s). 2020 Open Access This article is licensed under a Creative Commons Attribution 4.0 International License, which permits use, sharing, adaptation, distribution and reproduction in any medium or format, as long as you give appropriate credit to the original author(s) and the source, provide a link to the Creative Commons licence, and indicate if changes were made. The images or other third party material in this article are included in the article's Creative Commons licence, unless indicated otherwise in a credit line to the material. If material is not included in the article's Creative Commons licence and your intended use is not permitted by statutory regulation or exceeds the permitted use, you will need to obtain permission directly from the copyright holder. To view a copy of this licence, visit http://creativecommons.org/licenses/by/4.0/. The Creative Commons Public Domain Dedication waiver (http://creativecommons.org/publicdomain/zero/1.0/) applies to the data made available in this article, unless otherwise stated in a credit line to the data. 
higher than the indirect consumption from processed food and beverages in the past 20 years [6]. However, the trend of direct sugar consumption has been declining, while that of the indirect sugar consumption is increasing [6]. Total sugar consumption in Thailand has exceeded the WHO recommendation of $10 \%$ of total energy intake of $50 \mathrm{~g}$ of sugar per day and below $5 \%$ of total energy intake, which is $25 \mathrm{~g}$ per day for additional health benefits. Furthermore, sugar consumption in Thailand has increased from an average of $76.19 \mathrm{~g}$ per day in year 2000 to $104.46 \mathrm{~g}$ per day by 2015 [7]. The fraction of total sugar consumed in Thailand from SSB sources has increased from $15 \%$ in 2000 to $21 \%$ by 2015 , while that from non-SSB sources has decreased from $85 \%$ in 2000 to $79 \%$ by 2015 [7]. A review of national surveys and studies suggests that common food sources of sugar and indirect sugar consumption in all age groups were sweetened beverages, Thai desserts, and confectionery [8]. Among these food sources, sugarsweetened beverages (SSB) represent the largest source of sugar consumption $[8,9]$. In the last few decades, SSB consumption has been on the rise in many parts of the world including Thailand $[6,10]$. Twenty four percent of the Thai population consumed at least one serving of SSB daily, which contains sugar ranging from $10 \mathrm{~g}$ in dairy product and cereal drinks, to $34 \mathrm{~g}$ per serving in soft drinks $[9,11]$.

In an effort to reduce sugar consumption, an SSB tax policy has been implemented by several countries such as Hungary [12], France [13], Mexico [14], and some cities in the United States [15]. Recently, Australia, The Philippines [16], UK [17], India and South Africa [18] have taken the initiative to implement a similar SSB tax policy. As evidence suggest that SSB consumption decreases when price increases, leading to a reduction in average daily calorie intake and BMI $[17,19,20]$.

In 2017, the Thai Excise Department implemented a tiered SSB tax policy. The SSB tax was implemented because sugar consumption in Thailand has exceeded the WHO recommendation and due to the increasing prevalence of health problems linked to high sugar consumption, such as obesity (the prevalence of individuals with BMI $\geq 30 \mathrm{~kg} / \mathrm{m}^{2}$ has increased from $12.1 \%$ in 2004 to $19.8 \%$ in 2014 [21]), diabetes (prevalence of diabetes has increased from $7.1 \%$ in year 2004 to $10.85 \%$ in year 2014 among Thai population aged 20 years or older [21]), hypertension (prevalence of hypertension among the Thai population aged 20 years and older has increased from $45 \%$ in 2004 to $48.1 \%$ in 2014 [ [21]), and dental caries (prevalence of dental caries has increased from $85.6 \%$ in year 2000 to $86.7 \%$ in 2012 among Thai adults [22]). Since one of the health problems from high sugar consumption is the development of dental caries, it is important to understand from a policy perspective what impact the new SSB tax policy will have on the prevalence of dental caries. Similar studies have been conducted in other countries investigating SSB tax and its impact on dental caries [23-25], while other studies examined SSB tax and its impact on reduced sugar consumption, energy intake and obesity [26-29].

The Thai tiered SSB tax in 2017 adopted a mix tax rate system with both ad valorem and specific rate [30]. The ad valorem portion of the tax is calculated from the suggested retail price, while the specific tax component depends on the sugar content. The specific tax is generated as such: sugar content higher than $14 \mathrm{~g}$ per $100 \mathrm{ml}$ prompts high tax, sugar content of $8-14 \mathrm{~g}$ per $100 \mathrm{ml}$ prompts moderate tax, sugar content of $6-8 \mathrm{~g}$ per 100 $\mathrm{ml}$ prompts low tax and sugar content lower than $6 \mathrm{~g}$ per $100 \mathrm{ml}$ is not taxed at all. Upon implementation, this tax rate will increase every 2 years until 2023 [30]. SSB that will be subject to the SSB tax include packaged and ready to drink products such as carbonated soft drinks with added sugar, fruit and vegetable juices, coffee, tea, energy drinks and beverage concentrates for vending machines. With the SSB tax policy, it is expected that sugar consumption among the Thai population will reduce, eventually leading to a reduction in the prevalence of obesity, Type 2 diabetes and tooth decay [25]. However, the SSB tax is not applicable to other nonpackaged or non-ready to drink beverages such as herbal drinks, tea and coffee in coffee shops and street vendors. Aside from Thai desserts and snacks, sweet drinks from coffee shops and street vendors are common sources of added sugar consumed by the Thai population.

Oral health issues can be conceptualized as a complex system linked to multiple factors [31, 32], and these factors are diverse, myriad, context dependent and constantly changing. Failing to address that complexity can lead to an inadequate consideration of the dynamic relationships, diverse perspective and invisible boundaries that influence both SSB tax policy and oral health outcomes. Traditional epidemiological and economic approaches may be limited as they may not account for the non-linear and complex relationship among variables [31, 33]. A model-based study in Germany showed that a $20 \%$ increase in SSB tax was associated with a reduction in caries, especially among the young and low income population [25]. However, the effect of SSB tax on sugar consumption and dental caries is far from straightforward. Thus, it is uncertain if a tax increase will translate into lower sugar consumption and better oral health outcomes. Understanding the causal mechanisms through which the SSB tax will translate into lower sugar consumption and improved oral health is important in identifying a leverage point for interventions. Dental caries can also be prevented through behavioral change interventions, such as sugar consumption 
reduction, oral hygiene practices and the utilization of dental health care services. The aim of the study is to explore the expected impact of the new SSB tax policy and other alternative policies on oral health outcomes in Thailand, as measured through the prevalence and distribution of dental caries among the Thai population.

\section{Methods}

The systems science methodology of system dynamics was used [34, 35]. System dynamics modelling is a process of problem identification, causal hypothesis generation, diagramming the proposed causal relationships, translation of qualitative hypothesis into quantitative simulation, reliability testing and policy analysis [34, 35]. Qualitative system dynamics focuses on the use of causal hypothesis generation tools, such as causal loop diagram, to articulate and visualize our understanding of the complex relationships, dynamics, and interconnectedness between interacting variables that are affecting or are affected by the issue of interest. Meanwhile, quantitative system dynamics models consist of interacting sets of differential and algebraic equations developed from the translation of the qualitative causal loop diagram to a quantitative stock and flow model from a broad range of relevant empirical data to capture dynamic interrelationship [34-36]. The systems modelling approach has been used to analyze various oral health problems, including modelling oral healthcare service system in the Netherlands [37], participation in oral health promotion in New York [38] and caries reductions and cost savings from early childhood caries intervention in the United States $[39,40]$.

In order to gain a better understanding of the SSB tax policy and its likely impact on sugar consumption, an extensive literature review was conducted, leading to the development of guiding questions for an in-depth interview with stakeholders including public health policy makers, consumer foundation representatives, the Thai beverage association and tax excise department officers and health economists. Using insights from the in-depth interviews with stakeholders, a participatory stakeholders' engagement was organized to build stakeholder consensus, develop a deeper understanding, and map out the causal and dynamic relationships between SSB tax, sugar consumption and oral health outcomes. A detailed description of the in-depth interview with stakeholders and the participatory stakeholder engagements is reported in the reference as cited [41].

Briefly, a key informant interview was conducted in October 2016, and the key informants were identified through a stakeholder analysis. 'Stakeholders' herein refer to a group of knowledgeable individuals with complex personal and institutional experiences, beliefs and perceptions that can affect or are affected by the proposed SSB tax policy. A total of 7 informants were interviewed for 30 to $60 \mathrm{~min}$ in-person individually, using a semi-structured, open-ended questionnaire. The questionnaire covered a broad list of issues including sugar content in SSB and sugar consumption, general and oral health outcomes as a consequence of sugar consumption, concerns regarding the proposed SSB tax, and expected barriers and consequences. The interview was audio-recorded and transcribed. The purpose of the key informant interviews were to gain a deeper understanding of the perspectives of the multi-sector stakeholders on the proposed SSB tax, and its plausible consequences on sugar consumption and oral health outcomes. Following the key informant interviews, a participatory stakeholder engagement via Group Model Building (GMB) was conducted in February 2017. Details of the GMB process can be found in the references [32]. GMB refers to a system dynamics model building process, in which stakeholders are deeply and actively involved in the process of qualitative model construction through the exchange, assimilation, and integration of mental models into holistic system description [42]. Two GMB sessions lasting $3 \mathrm{~h}$ each were conducted with 10 stakeholders, including those involved in the key informant interviews. The outcome from the stakeholder engagement was a qualitative system dynamics model that describes the complex dynamic interrelationships of SSB tax policy, sugar consumption and dental caries.

A simulation model was developed following the stakeholders' engagement to simulate the bahaviour over time of key outcome variables, and presented to the stakeholders to verify the model structure and assumptions underlying postulated causal relationships. Both causal loop diagram and stock and flow diagram were developed using Vensim DSS version 6.4 (Ventana Inc). After verification, the model was parameterized using a series of empirical data. When data was not available, estimates from experts were used.

\section{Simulation model structure}

The dental caries simulation model projects the prevalence and distribution of dental caries severity among the Thai population 15 years and older. The simulation model consists of three interconnected sub-models: caries prevalence sub-model (SM1), dental service utilization sub-model (SM2), and oral health behavior sub-model (SM3) (Appendix A).

\section{Caries prevalence sub-model (SM1)}

The caries prevalence sub-model (SM1)-see Fig. 1projects the oral health status (OHS), measured herein by Decayed-Missing-Filled Teeth (DMFT) (Appendix B), among the Thai population 15 years and older. OHS was divided into four categories (see Table 1)-i.e. Very Low 


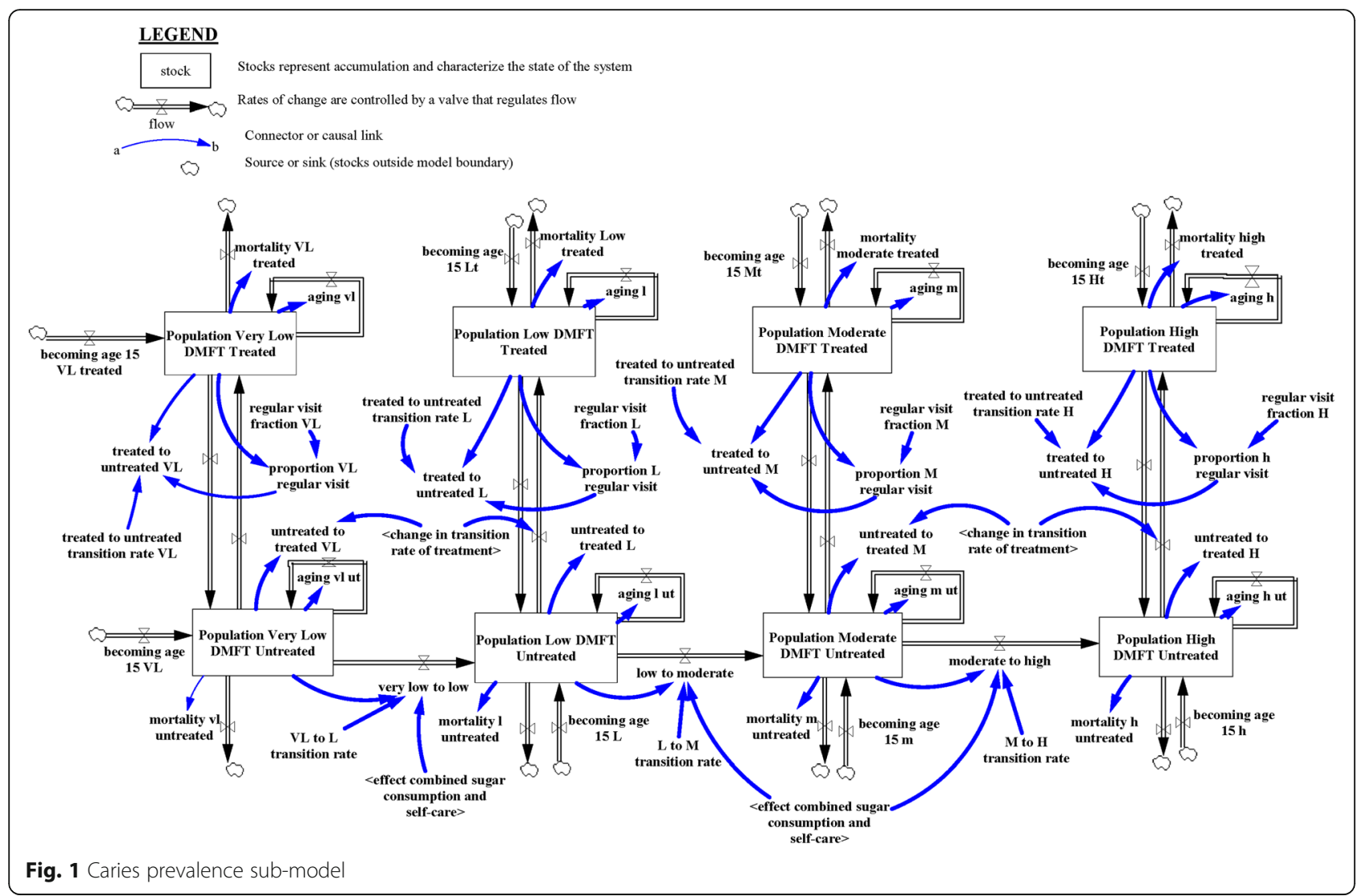

(VL) DMFT, Low (L) DMFT, Moderate (M) DMFT, and High (H) DMFT-based on WHO classification [43]. The WHO criteria of level of dental caries experience disaggregates the DMFT classification into two different age cohorts: children 12 years and adults of 35 to 44 years of age. For the purpose of this research, we used the DMFT classification of children 12 years of age for the Thai population 15-34 years of age; while the adult classification of 35 to 44 years of age was used for the Thai population 35 years and older. In addition, each OHS was further divided into two groups: treated and untreated dental caries. The treated population are individuals needing no normative treatment, or dental prosthesis, while the untreated population are individuals with dental treatment needs.

SM1 assumes progressive and unidirectional transitions across OHS. Transition rates across OHS groups were estimated using calibration, which is the process of adjusting model parameters to obtain an outcome comparable to available data (distribution of oral health outcomes). The transitions within each OHS is bidirectional, meaning an individual can move from treated to untreated and vice versa. The conceptualization of SM1 began with the instantiation of the simulation model, and the Thai population 15 years and older was distributed into the four OHS. The population in each OHS increases as (a) the population becoming 15 years old flows into that OHS and the new entrants (15 years old) are distributed across the four OHS (i.e. Very Low (VL) DMF, Low (L) DMFT, Moderate (M) DMFT, and High (H) DMFT); (b) when individuals in one OHS transition to another. Similarly, the numbers of population in each OHS decreases (a) via deaths and (b) when individuals in one OHS transition

Table 1 WHO severity criteria for level of dental caries experience in permanent dentition [43]

\begin{tabular}{lll}
\hline Oral health status (Dental caries experience) & Children 12 years DMFT (Teeth/person) & Adult 35-44 years DMFT (Teeth/person) \\
\hline Very low $(\mathrm{VL})$ & $<1.2$ & $<5.0$ \\
Low $(\mathrm{L})$ & $1.2-2.6$ & $5.0-8.9$ \\
Moderate $(\mathrm{M})$ & $2.7-4.4$ & $9.0-13.9$ \\
High $(\mathrm{H})$ & $>4.5$ & $>13.9$ \\
\hline
\end{tabular}


from that OHS to another OHS. SM1 accounts for aging within each health status to ensure that at the end of every year, the surviving population in each OHS transitions to the appropriate age cohort, since age is an important factor for death. Transitions from untreated to treated status are influenced by the change in uptake rate of treatment, which is derived from dental service utilization sub-model (SM2). Transitions from treated to untreated status are influenced by the regular dental visits fraction, which was calculated from the numbers of population who visited the dentists in the past year prior to the national oral health survey. Data from the Thai national oral health survey in 2000-2001 (S1), 2006-2007 (S2) and 2012 (S3) was used as the main data source.

\section{Dental service utilization sub-model (SM2)}

The dental service utilization sub-model (SM2) (Fig. 2) simulates the dynamics of dental services use. Dental services refer to care services for the purpose of the maintenance of healthy teeth, and includes examination and diagnosis of dental problems, restorative dentistry, periodontics, extraction of teeth under local anesthesia and curettage of infected socket, and preventive dentistry and oral health education. Here, the proportion of people using dental services (uptake rate of treatment) is affected by the number of new people using the services (herein referred to as net change in uptake rate). Net change in uptake rate (referring to the difference between the number of new people seeking dental treatment minus the number of people leaving dental treatment) is herein determined by the most current data on uptake rate (herein referred to as indicated uptake rate of dental services), last measured uptake rate of dental services (herein referred to as uptake rate of dental services), and time to adjust uptake rate of dental services. Indicated uptake rate of dental services is determined by access to dental services and affordability of dental care. Access to dental services focuses on availability of dental services, while affordability of dental services focuses on the ability of the population to pay for dental care services. The ratio of population per dental personnel, including dentists and dental nurses, was used as a proxy for access to dental services. It was assumed that increased access to dental care would increase the treatment uptake rate. Furthermore, affordability of dental health services is assumed to vary across socio-economic group. Low-income individuals are assumed to struggle with out-of-pocket costs of dental services, whereas high-income individuals are assumed to have no such problem. Accessibility and affordability of dental services are represented in the model as policy variables that could be further explored due to its potential impact on uptake rate of dental services.

\section{Oral health behavior sub-model (SM3)}

The oral health behavior sub-model (SM3) (see Fig. 3) models the dynamic relationship between oral health awareness, sugar consumption, and oral health self-care practice. Oral health awareness is the prevalence of oral health knowledge (i.e. awareness of oral diseases or risk factors or preventive measures) among the population. For the purpose of this research, the proportion of the

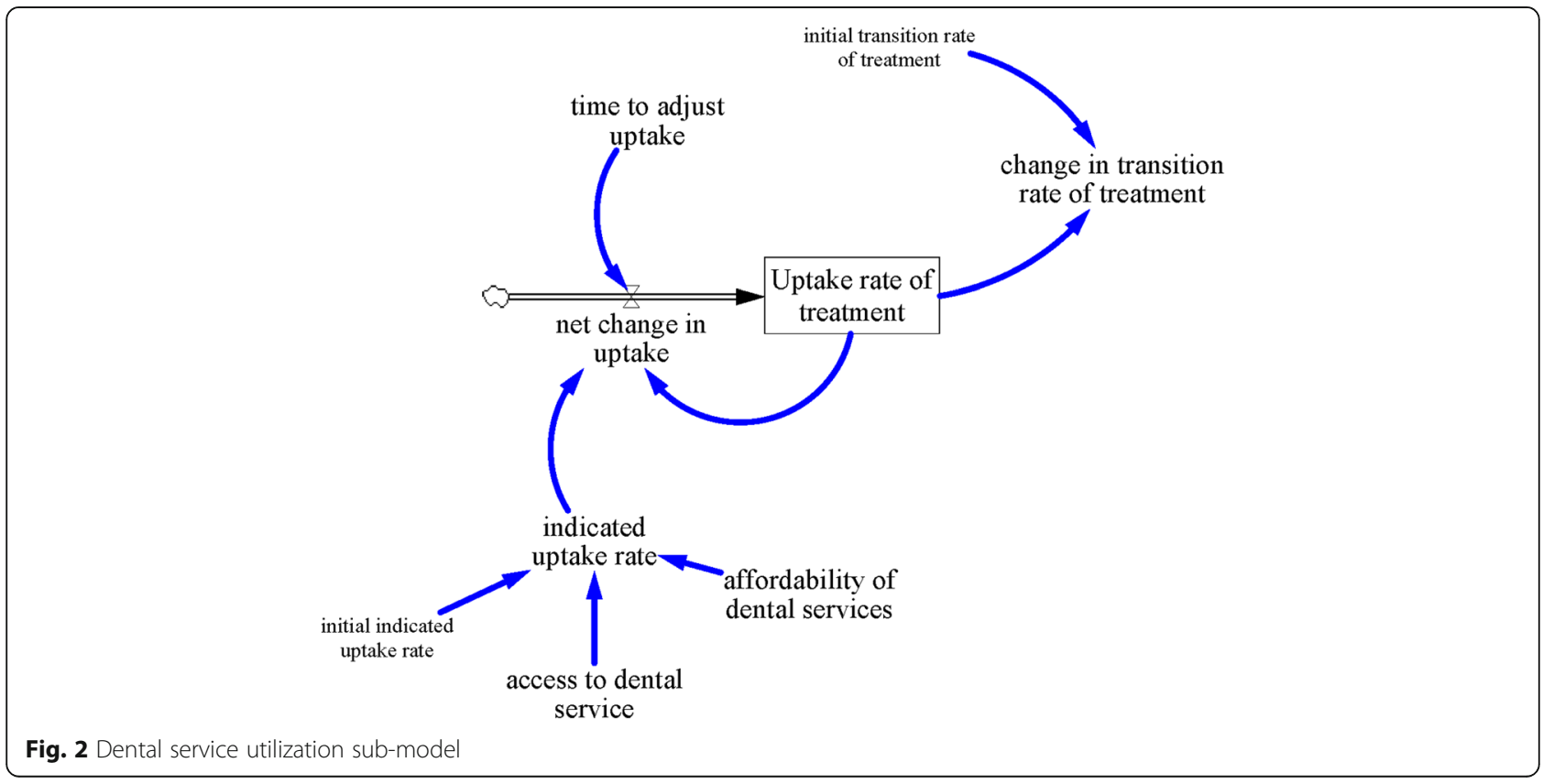




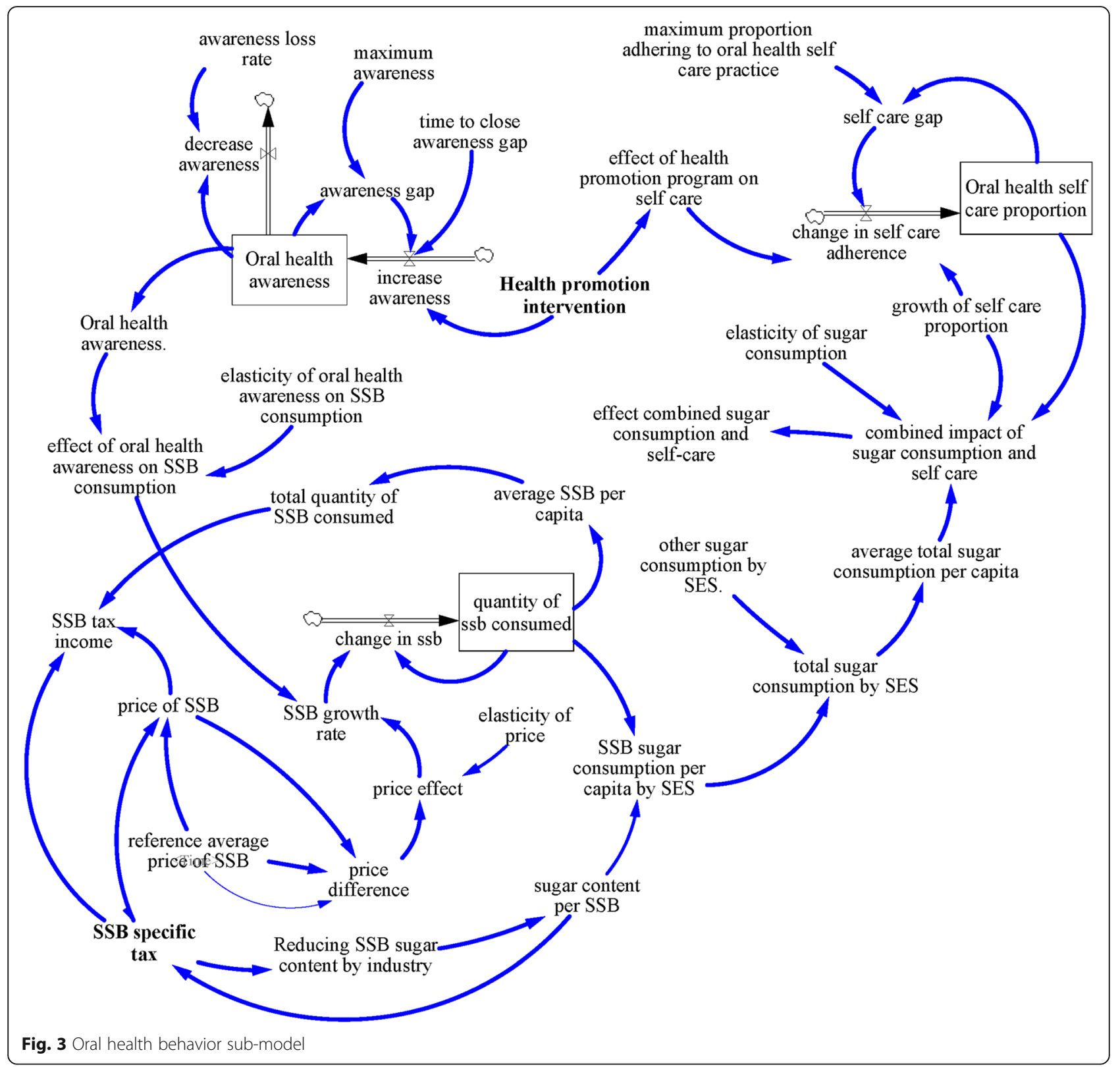

Thai population who receive oral health knowledge from television, social media, family and friends were used as a proxy for oral health awareness. In order to simplify the model structure for oral health awareness, we assumed a maximum level of oral health awareness achievable. Hence a maximum oral health awareness rate is compared with current oral health awareness rate to determine the oral health awareness gap. Any gap in oral health awareness is assumed to be closed by health promotion campaigns over time. Furthermore, loss in oral health awareness over time was represented, as determined by the loss rate of awareness.

Sugar consumption, which measures the average added sugar consumption, was divided into sugar consumed from sugar sweetened beverages (SSB) and other sources of sugar, including that consumed from coffee shops, street beverages, desserts and other food, and home sugar consumption. The SM3 model assumes that SSB consumption is affected by income; higher income individuals are assumed to consume more SSB relative to the lower-income individuals. Based on evidence from other studies [29], we postulated that SSB tax is likely to have less impact on the high-income group compared to the low-income group. In order to estimate the quantity of sugar intake from SSB, the quantity of SSB consumed was multiplied by the average sugar content per SSB. Lastly, current sugar consumption was compared to initial sugar consumption to 
derive relative sugar consumption to estimate the change in sugar consumption.

Self-care practice referred to the proportion of the population who brush their teeth at least twice a day with fluoride toothpaste. It was modeled as a stock which changes over time. Net change in self-care practice is determined through the gap between current self-care practice, maximum self-care practice and health promotion campaigns. As health promotion increases, self-care is assumed to increase simultaneously (Table 2).

\section{Policy simulation}

\section{Base-case}

This scenario represents the situation before the SSB tax was implemented. All parameters and key variables remain unchanged over the simulation run. This serves as a reference point for comparing four other scenarios.
SSB tax

This scenario implements the proposed SSB tax policy from 2018 to 2040. Table 3 shows the SSB tax in Thai Baht (Thailand currency) by SSB sugar content and the year of implementation. As indicated in Table 3, SSB with sugar content between 0 and $5.99 \mathrm{~g} / 100 \mathrm{ml}$ attracts no tax. However, SSB with sugar content between 6.0$8.0 \mathrm{~g} / 100 \mathrm{ml}$ attracts SSB tax that increases from 0.1 Thai Baht to 1 Thai Baht by 2040. Likewise, SSB with sugar content between $8.01-10.0 \mathrm{~g} / 100 \mathrm{ml}$ will attract SSB tax that rises from 0.3 Thai Baht to 3 Thai Baht by 2040. SSB with sugar content of $10.01-14.0 \mathrm{~g} / 100 \mathrm{ml}$ and $14.01-18.0 \mathrm{~g} / 100 \mathrm{ml}$ will attract SSB tax that increases from 0.5 Thai Baht and 1 Thai Baht, respectively to 5 Thai Baht by 2040. Lastly, SSB with sugar content above $18 \mathrm{~g} / 100 \mathrm{ml}$ will attract SSB tax that increases from 1 Thai Baht to 5 Thai Baht by 2040 .

Table 2 Model parameters

\begin{tabular}{|c|c|c|c|c|}
\hline \multirow{2}{*}{$\begin{array}{l}\text { Parameters } \\
\text { Dental caries sub-model (SM1) }\end{array}$} & \multicolumn{2}{|l|}{ Values } & \multirow[t]{2}{*}{ Unit } & \multirow[t]{2}{*}{ Source } \\
\hline & Age $15-34$ & Age $35+$ & & \\
\hline Regular visit fraction & & & Dimensionless/ year & {$[44]$} \\
\hline very low DMFT [female] & 0.229 & 0.148 & & \\
\hline very low DMFT [male] & 0.191 & 0.170 & & \\
\hline low DMFT [female] & 0.306 & 0.357 & & \\
\hline low DMFT [male] & 0.308 & 0.385 & & \\
\hline moderate DMFT [female] & 0.521 & 0.643 & & \\
\hline moderate DMFT [male] & 0.462 & 0.333 & & \\
\hline high DMFT [female] & 0.571 & 0.332 & & \\
\hline high DMFT [male] & 0.583 & 0.215 & & \\
\hline Treated to untreated transition & & & Dimensionless/ year & Expert estimation \\
\hline very low DMFT & 0.4 & 0.7 & & \\
\hline low DMFT & 0.78 & 0.58 & & \\
\hline moderate DMFT & 0.78 & 0.34 & & \\
\hline high DMFT & 0.7 & 0.75 & & \\
\hline avery Low To Low transition rate & $0.063(0.0504$ & & Dimensionless/year & Model calibration \\
\hline aLow To Moderate transition rate & $0.066(0.0528$ & & & \\
\hline aModerate To High transition rate & $0.063(0.0504$ & & & \\
\hline \multicolumn{5}{|l|}{ Dental health utilization sub-model (SM2) } \\
\hline Time to adjust uptake & 1 & & Year & Expert estimation \\
\hline Initial uptake rate & $V L 0.384, L 0$ & & Dimensionless & {$[44]$} \\
\hline \multicolumn{5}{|l|}{ Oral health behaviour sub-model (SM3) } \\
\hline Reference average price of SSB & \multicolumn{2}{|c|}{ Report on product price, 2000-2018 } & Thai Baht & [45] \\
\hline aDemand price elasticity & \multicolumn{2}{|c|}{$\begin{array}{l}\text { Low income }-1.46(-1.168-1.752) \\
\text { High income }-0.39(-0.312-0.468)\end{array}$} & Dimensionless & {$[46]$} \\
\hline Average sugar content per SSB & \multicolumn{2}{|l|}{$0.15(0.5-0.9)$} & $\mathrm{Kg} / \mathrm{litre}$ & {$[47]$} \\
\hline Other sugar consumption by SES [low income, high income] & \multicolumn{2}{|c|}{$\begin{array}{l}\text { Report from } 2000 \text { to } 2015 \text { and extrapolation after } 2015 \text { from 4y } \\
\% \text { change moving average }\end{array}$} & & [7] \\
\hline Initial self-care adherence & \multicolumn{2}{|l|}{0.529} & Dimensionless & [44] \\
\hline${ }^{\mathrm{a}}$ Elasticity of sugar consumption & \multicolumn{2}{|l|}{$0.6(0.4-0.72)$} & Dimensionless & Expert estimation \\
\hline 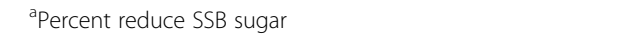 & \multicolumn{2}{|l|}{$0.8(0.5-0.9)$} & Dimensionless & Expert estimation \\
\hline
\end{tabular}

${ }^{\text {aParameters used for sensitivity analysis }}$ 
Table 3 SSB tax policy

\begin{tabular}{|c|c|c|c|c|}
\hline \multirow[b]{2}{*}{ Sugar Content (g/100 ml) } & \multicolumn{4}{|l|}{ Specific tax } \\
\hline & $\begin{array}{l}\text { 2018-2019 } \\
\text { (Thai Baht) }\end{array}$ & $\begin{array}{l}\text { 2021-2022 } \\
\text { (Thai Baht) }\end{array}$ & $\begin{array}{l}\text { 2023-2024 } \\
\text { (Thai Baht) }\end{array}$ & $\begin{array}{l}2025-2040 \\
\text { (Thai Baht) }\end{array}$ \\
\hline $0-5.99$ & 0 & 0 & 0 & 0 \\
\hline $6.0-8.0$ & 0.1 & 0.1 & 0.3 & 1 \\
\hline $8.01-10.00$ & 0.3 & 0.3 & 1 & 3 \\
\hline $10.01-14.00$ & 0.5 & 1 & 3 & 5 \\
\hline $14.01-18.00$ & 1 & 3 & 5 & 5 \\
\hline more than 18.00 & 1 & 5 & 5 & 5 \\
\hline
\end{tabular}

\section{Aggressive policy scenario}

This scenario consists of: (a) SSB tax policy scenario, (b) non-SSB sugar consumption scenario, and (c) dental care services use scenario. The SSB tax policy scenario is exactly the same as the SSB tax policy with different SSB tax rates for different SSB sugar content in years 2018 to 2020, 2021 to 2022, 2023 to 2024, and 2025 to 2040. However, the non-SSB sugar consumption scenario assumes that non-SSB sugar consumption will decrease $80 \%$ in comparison with the base-case sugar consumption from 2018 to 2040. Thus, non-SSB sugar consumption is assumed to decrease from $22.35 \mathrm{~kg} /$ person/year to $4.47 \mathrm{~kg} /$ person/year for low income individuals and $33.01 \mathrm{~kg} /$ person/year to $6.6 \mathrm{~kg} /$ person/year for high income individuals in 2018 (the base year for the policy implementation). Meanwhile, that for 2040 is assumed to decrease from $28.04 \mathrm{~kg} /$ person/year to $5.6 \mathrm{~kg} /$ person/ year for low income individuals, and $43.15 \mathrm{~kg} /$ person/ year to $8.63 \mathrm{~kg} /$ person/year for high income individuals. Likewise, the dental care services use scenario assumes that uptake rate of dental care services will increase 50\% from 39 to $50.85 \%$ in 2018 (the base year for the policy implementation) and remain unchanged to 2040.

\section{Sensitivity analysis}

Sensitivity analysis performed on all the scenarios proposed in the study aimed to observe the effect of parameter changes on the main outcomes of interest (population in each DMFT group and sugar consumption). Using multivariate sensitivity analysis, the parameters that were deemed to be sensitive to the outcomes of interest were varied by $\pm 20 \%$ and impact on the outcomes were measured at 95\% confidence level. Table 2 indicates the list of parameters included in the sensitivity analysis.

\section{Results}

Under the base-case scenario, the prevalence of dental caries, among the Thai population 15 years and older is projected to increase from $61.3 \%$ in 2010 to $74.9 \%$ by 2040. Implementation of SSB tax policy is expected to decrease the prevalence of dental caries by only $1 \%$ by
2040 , whereas the aggressive policy is projected to decrease prevalence of dental caries by $21 \%$ by 2040 . The mean DMFT values for individuals $15-34$ years, under the base-case is projected to increase from 2.42 in 2010 to 2.60 by 2040 . Similarly, the mean DMFT value under the SSB tax policy, by 2040 is 2.58 (representing $0.76 \%$ relative to the base-case), while that for the aggressive policy is 2.22, (representing 14.6\% reduction relative to the base-case). For those 35 years and older, the mean DMFT value is estimated to increase from 2.22 in 2010 to 2.92 by 2040 . By 2040, the mean DMFT for the SSB policy is projected to be 2.89 (which is $1.03 \%$ reduction), whereas that for the aggressive policy is 2.15 , representing $26.3 \%$ reduction.

Table 4 shows the projected distribution of the population by DMFT severity. For the base-case scenario, the population with low DMFT is projected to decrease from 9.95 million in 2010 to 9.76 million (9.63 million9.89 million) by 2040 , representing a reduction of $2 \%$. However, the population with moderate DMFT is projected to increase $18 \%$ from 8.37 million in 2010 to 9.87 million (9.73 million-9.96 million) by 2040; whereas those with high DMFT is also projected to increase 58\% from 12.56 million in 2010 to 19.79 million (19.58 million-20 million) by 2040 . In 2040 , the elderly population (65 years and older) is projected to constitute 21, 27 and $39 \%$ of the individuals with low, moderate and high DMFT, respectively. In addition, the proportion of untreated dental caries is projected to remain higharound 91\% - among those with low, moderate and high DMFT.

By 2040, the implementation of the SSB tax policy is projected to nominally increase the individuals with low DMFT by $1 \%$ compared to the base-case scenario; individuals with moderate and high DMFT are projected to decrease by 0.1 and $3 \%$, respectively, compared to the base-case scenario. Likewise, the proportion of untreated dental caries is projected to remain at $91 \%$ for all DMFT groups. Nonetheless, by 2040, the implementation of the aggressive policy is projected to increase the number of individuals with low DMFT by $18 \%$ compared to the base-case scenario, while that for moderate and high 
Table 4 Projected population by dental caries status (millions)

\begin{tabular}{llllllll}
\hline Outcomes & & 2010 & 2020 & 2030 & 2040 & \% change 2010-2040 & \% change to base-case \\
\hline Base-case & Very low DMFT & $19.52(19.43-19.61)$ & $17.70(17.56-17.85)$ & $15.52(15.35-15.70)$ & $13.20(13.02-13.38)$ & $-31 \%$ & - \\
& Low DMFT & $9.95(9.86-10.05)$ & $10.94(10.82-11.06)$ & $10.73(10.60-10.86)$ & $9.76(9.63-9.89)$ & $-2 \%$ & - \\
& Moderate DMFT & $8.37(8.30-8.43)$ & $9.52(9.42-9.61)$ & $10.09(9.98-10.20)$ & $9.87(9.73-9.96)$ & $18 \%$ & - \\
& High DMFT & $12.56(12.51-12.61)$ & $15.21(15.10-15.31)$ & $17.76(17.60-17.92)$ & $19.79(19.58-20.00)$ & $58 \%$ & - \\
SSB Tax Policy & Very low DMFT & $19.52(19.43-19.61)$ & $17.70(17.56-17.85)$ & $15.73(15.56-15.91)$ & $13.65(13.47-13.83)$ & $-30 \%$ & $3 \%$ \\
& Low DMFT & $9.95(9.86-10.05)$ & $10.94(10.82-11.06)$ & $10.76(10.63-10.88)$ & $9.88(9.75-10.01)$ & $-1 \%$ & $1 \%$ \\
& Moderate DMFT & $8.37(8.30-8.43)$ & $9.52(9.42-9.61)$ & $10.06(9.96-10.17)$ & $9.83(9.72-9.94)$ & $18 \%$ & $-0.1 \%$ \\
Aggressive Policy & Very low DMFT & $19.52(19.43-19.61)$ & $18.86(18.73-18.99)$ & $20.91(20.79-2104)$ & $21.49(21.37-21.62)$ & $10 \%$ & $-3 \%$ \\
& High DMFT & $12.56(12.51-12.61)$ & $15.20(15.10-15.31)$ & $17.54(17.38-17.70)$ & $19.24(19.03-19.44)$ & $53 \%$ & $63 \%$ \\
& Low DMFT & $9.95(9.86-10.05)$ & $10.91(10.80-11,03)$ & $11.46(11.35-11.56)$ & $11.48(11.38-11.58)$ & $15 \%$ & $18 \%$ \\
& Moderate DMFT & $8.37(8.30-8.43)$ & $9.34(9.25-9.43)$ & $9.37(9.30-9.44)$ & $8.92(8.86-8.98)$ & $7 \%$ & $-9.4 \%$ \\
& High DMFT & $12.56(12.51-12.61)$ & $14.26(14.17-14.35)$ & $12.35(12.27-12.43)$ & $10.70(10.63-10.77)$ & $-15 \%$ & $-46 \%$ \\
\hline
\end{tabular}

DMFT are projected to decrease significantly by 9.4 and $46 \%$ respectively compared to the base-case scenario. Furthermore, the proportion of untreated dental caries is projected to decrease significantly to $58 \%$ for low DMFT, $49 \%$ for moderate DMFT, and $62 \%$ for high DMFT.

\section{Discussion}

Based on the simulation analysis, the implementation of the proposed tiered SSB tax in Thailand is expected to reduce SSB consumption among both the low- and highincome groups, with the highest impact observed in the longer term due to higher SSB tax rates in later years. This finding is consistent with other studies [48-50]. The main insight from this research suggests that SSB tax policy alone is unlikely to have any meaningful impact on oral health outcomes, as defined by dental caries, unless it is accompanied by a comprehensive policy that aims to reduce total sugar intake from non-tax sugary food sources. Countries where a majority of the sugar consumed are from non-tax sugary food and beverages, especially Asian countries where street food culture is ubiquitous and contributes disproportionately to sugar intake, may find this insight especially relevant. The policy implications of this insights are: (a) countries with a significant proportion of sugar intake from nontax sources, such as coffee shops, and high sugar content desserts and food from street shops, should design innovative policies to reduce sugar consumption; (b) although over-reliance on SSB tax will increase resources for other public health interventions, it is unlikely to produce the expected health outcomes in dental caries; (c) policies designed to reduce sugar intake from nonSSB sources will require significant stakeholder engagement to increase the likely buy-in from stakeholders.

Although the simulation model presented has substantial implications for policy, it should be interpreted with caution. The main strength of this study is the active engagement of stakeholders in the development and validation of the simulation model, as well as the synthesis of data from various sources to populate the simulation model in order to evaluate the likely impact of the SSB policy and alternative policies on dental caries. Additionally, the simulation model allows policymakers to observe the likely impact of their policies in-silico before they are implemented. This research is an exercise to inform policymakers in Thailand of the likely impact of the proposed SSB tax policy on the prevalence of dental caries. This is important because the proposed SSB tax and its impact on sugar consumption and health outcomes (such as dental caries) is a systemic-pluralist problem. It is systemic because the problem lies in the complexity of the system which is often partially observable, probabilistic in nature, evolving over time, and subject to behavioral influences [51]; it is pluralistic because possible solutions to the problem are diverse and might be acceptable by some stakeholders but not to others [51]. Hence, this research exercise could be used by policymakers to engage other stakeholders to discuss policy options, modify model assumptions and structure and consider holistically, the impact of the proposed SSB tax on other health outcomes.

However, one limitation of the study is that a change in the projected population will affect the number of people by DMFT groups. Furthermore, due to lack of longitudinal data, we were unable to estimate and use evidence-based transition rates across different DMFT groups by age, gender and socio-economic groups, leading to a likely under or overestimation of the distribution of the population by DMFT groups.

\section{Conclusion}

In this study, a simulation model was used to evaluate the impact of a proposed tiered SSB tax in Thailand on dental caries among the Thai population. The results suggest that without combining SSB tax with a comprehensive policy that aims to reduce total sugar intake 
from non-SSB sources, implementing SSB tax alone will have minimal impact on dental caries. The simulation model presented can not only provide policy makers with additional insight to support future oral health policy planning efforts, but also guide the general population towards making healthier choices.

\section{Appendix A}

\section{Caries Prevalence sub-Model (SM1)}

This sub-model disaggregates the population of Thailand 15 years and older into four oral health status (i.e. population Very Low DMFT, population low DMFT, population moderate DMFT, and population high DMFT). To differentiate between individual treated and untreated, each oral health status was divided into two treatment status (i.e. untreated and treated); as a result, eight oral health status were obtained (population Very Low DMFT untreated, population Very Low DMFT treated, population low DMFT untreated, population low DMFT treated, population moderate DMFT untreated, population moderate DMFT treated, population high DMFT untreated, and population high DMFT treated). The caries prevalence sub-model operates as follows: at the beginning of each year, the population becoming 15 years (which is derived from the variable "population") which comes from a validated population model; is divided into the eight oral health status. The assumption here is that individuals becoming 15 years could be in any one of the eight oral health status, thus individuals becoming 15 years is divided into eight groups (i.e. becoming age 15 very low untreated, becoming age 15 very low treated, becoming age 15 low untreated, becoming age 15 low treated, becoming age 15 moderate untreated, becoming age 15 moderated treated, becoming age 15 high untreated, and becoming age 15 high treated). The caries prevalence model assumes that individuals with untreated dental caries can progress from one oral health status to the other, while individual treated individual are assumed remain in the same oral health status; and that transition is unidirectional (people can only progress to the worse oral health status). Thus, population very low DFMT untreated is assumed to progress to population low DMFT untreated over time; and population low DMFT untreated is assumed to progress to population moderate DMFT untreated. Lastly, population moderate DMFT untreated is assumed to progress to population high DMFT untreated over time. The progression from one oral health status to the other is determined by transition rate and the effect of combined sugar consumption and self-care. The population in each oral health status is further disaggregated by single age cohort (age 15 to age 100 and over). The aging process is represented in the model by the variables (aging vk ut, aging $\mathrm{vl}$, aging $\mathrm{l} u t$, aging $\mathrm{l}$, aging $\mathrm{m} u t$, aging $\mathrm{m}$, aging $\mathrm{h}$ ut, and aging h). the aging process works as follows, ag the end of each year, the population in each cohort is shifted to the next age cohort to account for aging (thus individuals in cohort age 15 will shift to age 16, while those in age 16 will shift to age 17 until age 100 which is the last age cohort). The movement of individuals from untreated to treated is determined by regular visit fraction (which represent the proportion of population untreated who start receiving regular dental care services). Likewise, individuals move from treated to untreated oral health status when they stop receiving dental care services.

\section{Dental service utilization sub-model (SM2)}

The dental service utilization sub-model simulates the uptake rate of dental treatment. Uptake rate dental treatment increase by net change in uptake rate-which is the difference between individual who are taking up new dental treatment and those leaving dental treatment (attrition). The net change in uptake of treatment is affected by indicated uptake rate-which is determined by affordability of dental services, access to dental services and initial indicated uptake rate. As uptake rate of treatment increases, the transition rate from untreated to treated is assumed to change over time.

\section{Oral health behavior sub-model (SM3)}

The oral health behavior sub-model simulates the impact of health promotion intervention on oral health self-care and oral health awareness, and its subsequent impact on SSB consumption. In the model, health promotion intervention is assumed increase oral health awareness, while oral health awareness decreases due to awareness loss rate. As oral health awareness, and price of SSB increase, it is assumed to affect the SSB growth rate-the increase in oral health awareness and SSB price will decrease the increase in SSB growth rate. As SSB growth rate decreases, quantity of SSB consumed is assumed to decrease, leading to lower average SSB per capita and total quantity of SSB consumed. The price of SSB is affect by reference average price of SSB and SSB specific tax. The price difference is the difference between reference average price before the SSB tax and price of SSB after SSB tax. As price difference increase, the effect of price on SSB consumption is assumed to increase, thus decreasing the amount of SSB consumed. In addition, the introduction of SSB specific tax is assumed to decrease the sugar content in SSB, thus eventually decreasing the total sugar consumption. As SSB sugar consumption per capita by SES (socio-economic status) decreases, total sugar consumption by SES is assumed to decrease, which together with change in oral health selfcare is assumed to impact of transition to worse oral health status. 


\section{Appendix B}

\section{Calculation of DMFT [43]}

DMFT and DMFS measures dental caries severity or intensity in an individual. DMFT and DMFS are means to numerically express the caries severity and are obtained by calculating the number of (a) Decayed (D), (b) Missing $(\mathrm{M})$, (c) Filled (F) teeth ( $\mathrm{T})$ or surfaces $(\mathrm{S})$. It is thus used to get an estimation illustrating how much the dentition until the day of examination has become affected by dental caries. It is either calculated for 28 (permanent) teeth, excluding 18, 28, 38 and 48 (the "wisdom" teeth) or for 32 teeth (The Third edition of "Oral Health Surveys - Basic methods", Geneva 1987, recommends 32 teeth). Thus: (a) how many teeth have caries lesions (incipient caries not included)? (b) how many teeth have been extracted? (c) how many teeth have fillings or crowns? The sum of the three figures forms the DMFTvalue. For example: DMFT of $4-3-9=16$ means that 4 teeth are decayed, 3 teeth are missing and 9 teeth have fillings. It also means that 12 teeth are intact. Note: If a tooth has both a caries lesion and a filling it is calculated as D only. A DMFT of 28 (or 32, if "wisdom" teeth included) is maximum, meaning that all teeth are affected. A more detailed index is DMF calculated per tooth surface, DMFS. Molars and premolars are considered having 5 surfaces, front teeth 4 surfaces. Again, a surface with both caries and filling is scored as $D$. maximum value for DMFS comes to 128 for 28 teeth. For the primary dention, consisting of maximum 20 teeth, the corresponding designations are "deft" or "defs", where "e" indicates "extracted tooth".

\section{Abbreviations}

DMFT: Decayed-Missing-Filled Teeth; H: Hight DMFT; L: Low DMFT; M: Moderate DMFT; OHS: Oral health status; S1: Year 2000-2001; S2: Year 2006-2007; S3: Year 2012; SM1: Caries prevalence sub-model; SM2: Dental service utilization sub-model; SM3: Oral health behavior sub-model; SSB: Sugar-sweetened beverage; VL: Very Low DMFT

\section{Acknowledgements}

We thank all stakeholders and experts for the input of the modeling process. We extend our gratitude to the Department of Social and Preventive Medicine, Faculty of Medicine, Chulalongkorn University for their support.

\section{Authors' contributions}

NU contributed to conception, design, data acquisition, analysis and interpretation, drafted and critically revised the manuscript. PH and JPA contributed to design, analysis and data interpretation, and critically revised the manuscript. VK and PP contributed to data acquisition and drafted manuscript. All authors read and approved the final manuscript for publication.

\section{Funding}

The study was funded by a grant (PHD/0128/2558) from The Royal Golden Jubilee (RGJ) Ph.D. Programme, The Thailand Research Fund (TRF). The funder had no role in the study design, data collection and analysis, decision to publish or preparation of the manuscript. The website of the funder is at http://rgj.trf.or.th/main/home/.

\section{Availability of data and materials}

The datasets used and/or analyzed during the current study are available from the corresponding author on reasonable request.

\section{Ethics approval and consent to participate}

The study protocol was approved by the Research Ethics Committee of the Faculty of Medicine, Chulalongkorn University, Thailand (No. 503/59). Written consent was obtained from all participants.

\section{Consent for publication}

Not applicable.

\section{Competing interests}

The authors declare that they have no competing interests.

\section{Author details}

${ }^{1}$ Department of Community Dentistry, Faculty of Dentistry, Chulalongkorn University, Bangkok, Thailand. ${ }^{2}$ Department of Preventive and Social Medicine, Faculty of Medicine, Chulalongkorn University, Bangkok, Thailand. ${ }^{3}$ Health Services and Systems Research, Duke-NUS Medical School, Singapore, Singapore. ${ }^{4}$ Bureau of Dental Health, Department of Health, Ministry of Public Health, Nonthaburi, Thailand. ${ }^{5}$ Saw Swee Hock School of Public Health, National University of Singapore, Lower Kent Ridge Road, Singapore, Singapore.

Received: 26 April 2019 Accepted: 3 March 2020

Published online: 18 March 2020

\section{References}

1. Masood M, Newton T, Bakri NN, Khalid T, Masood Y. The relationship between oral health and oral health related quality of life among elderly people in United Kingdom. J Dent. 2017;56:78-83.

2. Locker D, Grushka M. The impact of dental and facial pain. J Dent Res. 1987; 66(9):1414-7.

3. Hayes A, Azarpazhooh A, Dempster L, Ravaghi V, Quiñonez C. Time loss due to dental problems and treatment in the Canadian population: analysis of a nationwide cross-sectional survey. BMC Oral Health. 2013;13(1):17.

4. Moynihan P, Petersen PE. Diet, nutrition and the prevention of dental diseases. Public Health Nutr. 2004;7(1a):201-26.

5. Marshall TA. Preventing dental caries associated with sugar-sweetened beverages. J Am Dent Assoc. 2013;144(10):1148-52.

6. Rattanarungsima K. The sugar consumption of Thai population during 19972010. Thai J Dent Public Health. 2012;17(2):23-30.

7. Office of the Cane and Sugar Board, Ministry of Industry. Summary of sugar sales for domestic consumption, Thailand. 2016. http://www.sugarzone.in. th/ Accessed 21 June 2017.

8. Kriengsinyos W, Chan P, Amarra MSV. Consumption and sources of added sugar in Thailand: a review. Asia Pac J Clin Nutr. 2018;27(2):262.

9. National Bureau of Agricultural Commodity and Food Standards. Food consumption data of Thailand 2007-2010. Bangkok: Ministry of Agriculture and Cooperative; 2010

10. World Health Organization. Guideline: Sugars intake for adults and children. Geneva; 2015. https://www.who.int/nutrition/publications/guidelines/ sugars_intake/en/. Accessed 12 Jan 2016.

11. National Statistical Office. The 2013 survey on food consumption behaviour. Bangkok; 2014. http://web.nso.go.th/en/survey/data_survey/570602_ executive_survey_on_food_consumption_13.pdf. Accessed 25 Aug 2016.

12. European competitiveness and sustainable industrial policy consortium. Food taxes and their impact on competitiveness in the agri-food sector: Rotterdam; 2014. https://ec.europa.eu/growth/content/food-taxes-and-theirimpact-competitiveness-agri-food-sector-study-0_en. Accessed 25 Mar 2016.

13. Marron DB, Gearing ME, Iselin J. Should we tax unhealthy foods and drinks? 2015. http://ssrn.com/abstract=2703598. Accessed 15 June 2016.

14. Grogger J. Soda taxes and the prices of sodas and other drinks: evidence from Mexico. AJAE. 2017;99(2):481-98.

15. Cawley J, Frisvold D. The incidence of taxes on sugar-sweetened beverages: the case of Berkeley, California. J Policy Anal Manage. 2017;36(2):303-26.

16. House of representatives, Republic of the Philippines. Imposing excise tax on sugar sweetened beverages by inserting a new section 150-A in the National Internal Revenue code of 1997. 2016. http://www.congress.gov.ph/ legisdocs/basic_17/HB00292.pdf. Accessed 15 July 2017. 
17. Briggs ADM, Mytton OT, Kehlbacher A, Tiffin R, Elhussein A, Rayner M, Jebb SA, Blakely T, Scarborough P. Health impact assessment of the UK soft drinks industry levy: a comparative risk assessment modelling study. Lancet Public Health. 2017;2(1):e15-22.

18. Duckett $\mathrm{S}$, Swerissen $H$. A sugary drinks tax: recovering the community costs of obesity: Grattan Institute; 2016. https://grattan.edu.au/wp-content/ uploads/2016/11/880-A-sugary-drinks-tax.pdf. Accessed 10 Jan 2017.

19. Fletcher J, Frisvold D, Tefft N. The effects of sotf drinks taxes on child and adolescent consumption and weight outcomes. J Public Econ. 2010;94(1112):967-74.

20. Lin B-H, Smith TA, Lee J-Y, Hall KD. Measuring weight outcomes for obesity intervention strategies: the case of a sugar-sweetened beverage tax. Econ Hum Biol. 2011;9(4):329-41.

21. Aekplakorn W, Chariyalertsak S, Kessomboon P, Assanangkornchai S, Taneepanichskul S, Putwatana P. Prevalence of diabetes and relationship with socioeconomic status in the Thai population: National Health Examination Survey, 2004-2014. J Diabetes Res. 2018;2018:8. https://doi.org/ $10.1155 / 2018 / 1654530$

22. Bureau of Dental Health, Department of Health, Ministry of Public Health. The 8th Thailand National Oral Health Survey Report 2017. Bangkok: Sam Charoen Commercial Company Limited; 2018.

23. Jevdjevic M, Trescher AL, Rovers M, Listl S. The caries-related cost and effects of a tax on sugar-sweetened beverages. Public Health. 2019;169:12532.

24. Sowa PM, Keller E, Stormon N, Lalloo R, Ford PJ. The impact of a sugarsweetened beverages tax on oral health and costs of dental care in Australia. Eur J Pub Health. 2018;29(1):173-7.

25. Schwendicke F, Thomson WM, Broadbent JM, Stolpe M. Effects of taxing sugar-sweetened beverages on caries and treatment costs. J Dent Res. 2016;95(12):1327-32

26. Cabrera Escobar MA, Veerman JL, Tollman SM, Bertram MY, Hofman KJ. Evidence that a tax on sugar sweetened beverages reduces the obesity rate: a meta-analysis. BMC Public Health. 2013;13(1):1-10.

27. Nakhimovsky SS, Feigl AB, Avila C, O'Sullivan G, Macgregor-Skinner E, Spranca M. Taxes on sugar-sweetened beverages to reduce overweight and obesity in middle-income countries: a systematic review. PLoS One. 2016; 11(9):e0163358. https://doi.org/10.1371/journal.pone.0163358.

28. Teng AM, Jones AC, Mizdrak A, Signal L, Genç M, Wilson N. Impact of sugarsweetened beverage taxes on purchases and dietary intake: systematic review and meta-analysis. Obes Rev. 2019;20(9):1187-204.

29. Backholer K, Sarink D, Beauchamp A, Keating C, Loh V, Ball K, Martin J, Peeters $A$. The impact of a tax on sugar-sweetened beverages according to socio-economic position: a systematic review of the evidence. Public Health Nutr. 2016;19(17):3070-84.

30. Thai Department of Finance. Excise Act, B.E. 2560 (2017). Bangkok; 2017. http://web.krisdika.go.th/data//document/ext809/809872_0001.pdf. Accessed 4 Jan 2018.

31. Jayasinghe S. Social determinants of health inequalities: towards a theoretical perspective using systems science. Int J Equity Health. 2015;14: 71. https://doi.org/10.1186/s12939-015-0205-8.

32. Norman CD. Health promotion as a systems science and practice. J Eval Clin Pract. 2009;15(5):868-72.

33. Newton JT, Bower EJ. The social determinants of oral health: new approaches to conceptualizing and researching complex causal networks. Community Dent Oral Epidemiol. 2005;33(1):25-34.

34. Forrester JW. System dynamics and the lessons of 35 years. In: De Greene KB, editor. A systems-based approach to policymaking. Boston: Springer; 1993. p. 199-240.

35. Ansah JP, Matchar DB, Love SR, Malhotra R, Do YK, Chan A, Eberlein R. Simulating the impact of long-term care policy on family eldercare hours. Health Serv Res. 2013;48(2 Pt 2):773-91.

36. Ansah JP, Matchar DB, Koh V, Schoenenberger L. Mapping the dynamic complexity of chronic disease care in Singapore: using group model building in knowledge elicitation. Syst Res Behav Sci. 2018;35(6):759-75. https://doi.org/10.1002/sres.2517.

37. Bronkhorst E, Wiersma T, Truin G. Using complex system dynamics models: an example concerning the Dutch dental health care system. In: Proceedings of the 1991 International System Dynamics Conference; 1991. p. $155-63$.

38. Metcalf SS, Northridge ME, Widener MJ, Chakraborty B, Marshall SE, Lamster IB. Modeling social dimensions of oral health among older adults in urban environments. Health Educ Behav. 2013;40(1 suppl):63S-73S. https://doi.org/ 10.1177/1090198113493781.

39. Hirsch GB, Edelstein BL, Frosh M, Anselmo T. A simulation model for designing effective interventions in early childhood caries. Prev Chronic Dis. 2012;9:E66.

40. Edelstein BL, Hirsch G, Frosh M, Kumar J. Reducing early childhood caries in a Medicaid population: a systems model analysis. J Am Dent Assoc. 2015; 146(4):224-32.

41. Urwannachotima N, Hanvoravongchai P, Ansah JP. Sugar-sweetened beverage tax and potential impact on dental caries in Thai adults: an evaluation using the group model building approach. Syst Res Behav Sci. 2019;36(1):87-99.

42. Vennix JA. Group model building facilitating team learning using system dynamics. Chichester: Wiley; 1996.

43. World Health Organization. Oral health surveys: basic methods. 5th ed. Geneva; 2013. https://www.who.int/oral_health/publications/978924154864 9/en/. Accessed 15 Jan 2015.

44. Bureau of Dental Health, Department of Health, Ministry of Public Health. The 5th Thailand National Oral Health Survey Report 2000-2001. Bangkok; 2002.

45. Bureau of Trade and Economic Indices, Ministry of Commerce. Product retai price 2000-2015. https://data.moc.go.th/OpenData/CPIIndexes. Accessed 10 Jan 2015.

46. Bhadrakom C. Economic analysis of overnutrition in Thailand. PhD thesis. Reading: University of Reading; 2014.

47. Bureau of Food and Nutrition, Ministry of Public Health. Thailand Sugar contents in drinks. http://food.fda.moph.go.th/data/document/2558/CS_ sugar.pdf. Accessed 13 May 2015.

48. Guerrero-López CM, Unar-Munguía M, Colchero MA. Price elasticity of the demand for soft drinks, other sugar-sweetened beverages and energy dense food in Chile. BMC Public Health. 2017;17(1):180.

49. Colchero MA, Salgado JC, Unar-Munguía M, Hernández-Ávila M, RiveraDommarco JA. Price elasticity of the demand for sugar sweetened beverages and soft drinks in Mexico. Econ Hum Biol. 2015;19:129-37.

50. Lee J, Giannobile W. Taxes on sugar-sweetened beverages a strategy to reduce epidemics of diabetes, obesity, and dental caries? J Dent Res. 2016; 95(12):1325-6. https://doi.org/10.1177/0022034516668788.

51. Jackson MC, Keys P. Towards a system of systems methodologies. J Oper Res Soc. 1984:35(6):473-86.

\section{Publisher's Note}

Springer Nature remains neutral with regard to jurisdictional claims in published maps and institutional affiliations.

Ready to submit your research? Choose BMC and benefit from:

- fast, convenient online submission

- thorough peer review by experienced researchers in your field

- rapid publication on acceptance

- support for research data, including large and complex data types

- gold Open Access which fosters wider collaboration and increased citations

- maximum visibility for your research: over $100 \mathrm{M}$ website views per year

At BMC, research is always in progress.

Learn more biomedcentral.com/submissions 